\title{
A longitudinal study of the deciduous, mixed and permanent dentition evaluating the antero-posterior canine relationship
}

\author{
REBECA DI NICOLÓ*, CRISTIANI DE SIQUEIRA BARBOSA* , ANTONIO CARLOS GUEDES PINTO**,
} JAMES MCNAMARA***

\section{Abstract}

A longitudinal study was undertaken to assess the development of the antero-posterior canine relationship. For this purpose, 180 lower and upper study casts were analized during the deciduous, mixed and permanent dentition, in a total of 540 study casts. The subjects were selected from the University of Michigan Elementary and Secondary School Growth Study (UMGS). None of the subjects had received orthodontic treatment. Results showed that Class I canine relationship was the most frequent relationship during all period studied. Canine Class II tendency cases were the most stable relationship, followed by Class I and Class II cases.

\section{UNITERMS}

Occlusion; canine relationship, longitudinal study.

NICOLÓ, R. et al. Estudo longitudinal da relação dos caninos nas dentições decídua, mista e permanente. Pós-Grad Rev Fac Odontol São José dos Campos, v.4, n.1, p. 7-11, jan./abr., 2001.

\section{Resumo}

O objetivo deste estudo foi de avaliar a relação ântero-posterior dos caninos durante três períodos distintos de desenvolvimento. Desta forma, 180 modelos de estudo superiores e inferiores foram analisados durante os períodos das dentições decídua, mista e permanente, totalizando 540 modelos. Os modelos foram selecionados do acervo da The University of Michigan Elementary and Secondary Growth Study (UMGS). Nenhum dos pacientes foi submetido a qualquer tipo de tratamento ortodôntico. Os resultados revelaram que a relação de Classe I foi a mais frequente nos três períodos estudados, e a relação de Classe II tendência foi a mais estável, seguida pelos casos de Classe I e Classe II, quando avaliada longitudinalmente.

\section{UNITERMOS}

Oclusão, relação dos caninos, estudo longitudinal

\section{INTRODUCTION}

The human dental arches undergo visible alterations as they grow and adapt, a phenomenon particularly noticeable during the transition from the deciduous to the early permanent dentition. Characteristics of occlusion within the deciduous, mixed and permanent dentition in a "normal population" can be used as a reference by clinicians, orthodontics and pedodontics when analizing patients.

\footnotetext{
* Department of Social Dentistry and Pediatric Dentistry, São José dos Campos - UNESP Av. Francisco José Longo, 777 São José dos Campos/SP CEP 12245-000 - Fone: 3218166 R. 1300 / e-mail: nicolo@fosjc.unesp.br

*** Department of Orthodontics and Pediatric Dentistry, Center for Human Growth and Development, The University of Michigan, Ann Arbor, Michigan.
} 
Research regarding these developmental changes may contribute to the knowledge of the details of this transition, specially longitudinal studies. The development of canine relationship represents an important factor when classifying orthodontic patients.

Baume ${ }^{2}$ (1950), in your first article of a series of four published in 1950, studied the biogenesis of the deciduous dentition in 30 children. Results showed that the antero-posterior canine relationship was stable during the period of the deciduous dentition. In your second article, Baume ${ }^{3}(1950)$ accomplished a longitudinal sample involving 60 patients, which were recorded before and after the eruption of the first permanent molars. It was verified that, after the eruption of the first permanent molars, the measure of the distance between the distal surfaces of the second deciduous molars and the distal surfaces of the deciduous canine in the mandibular arch, decreased between 1,0 and $2,0 \mathrm{~mm}$. Concomitant to that process, there was a simultaneous closing of the primate spaces in the mandibular arch and the deciduous molars were moved to these spaces.

Foster \& Grundy ${ }^{4}$, (1986), studied a longitudinal sample of 60 patients, during the periods of the deciduous and permanent dentition. The objective of this study was that some characteristics of the occlusion present during the deciduous dentition could be present when the permanent dentition was established. The canine relationship was measured in millimeters in relation to the existent discrepancy for an ideal relationship. The measures were made separately for each hemi-arch, and obtained between 5 and 12 years of age. The results showed none antero-posterior alterations in $50 \%$ of the sample, between the deciduous and permanent canines. When the alteration was present, the majority showed a change in direction to Angle's Classe II, and only 5 cases showed an alteration in direction to Angle's Classe III. These results were quite similar when considering right and left hemi-arches. Mean values of these movements were relatively small $(1,4$ to $2,48 \mathrm{~mm}$ ), although in one case it presented an alteration of 7,0mm in direction to Angle's Class III.

The objective of this study was to evaluate the development of canine relationship in a longitudinal sample, including the deciduous, mixed and permanent dentition.

\section{Materials and Methods}

Articulated maxillary and mandibular dental casts from 90 subjects were selected from The University of Michigan Elementary and Secondary School Growth Study (UMGS). The Michigan Growth Study is comprised of longitudinal cephalometric and dental casts data from children who were enrolled in the laboratory school on the University of Michigan campus (Riolo et al ${ }^{6}$, 1974; Moyers et al. $\left.{ }^{5}, 1976\right)$. An effort was made to identify all subjects on whom at least one set of dental cast was available in the deciduous, mixed and permanent dentition and who had not undergone any type of orthodontic treatment. As these data originally were obtained during a period of time (i.e., 1940-1968) when early orthodontic treatment usually was not initiated, it was felt that this data represented the occlusions of a reasonable longitudinal sample.

The sample was defined on the basis of dental developmental, not chronological age. Therefore, 540 study casts from 90 subjects were selected. All subjects presented with one set of study casts representing the deciduous, mixed and permanent dentition. Subjects varied from a minimum of 3 years and 3 months and maximum of 21 years and 9 months.

The deciduous canines were used for the classification during the deciduous and mixed dentition, while in the permanent dentition the reference was the permanent canines. The arches were classified by Angle ${ }^{1}$ (1899) as Class I, Class II and Class III, as well as its tendencies.

\section{Results}

The results showed that Class I relationship was the most prevalent during the three studied periods. It was verified that Class I cases increased during the mixed dentition, but it decreased after the eruption of the second permanent molars, being less prevalent when comparing to the beginning of the study. An inverse relationship was verified for Class II and Class II tendency cases, in other words, its percentages decreased during the mixed dentition, and since then, increased during the period of the permanent dentition. The second most frequent relationship found was the ones of Class II tendency cases, followed by Class II. Class III and Class III tendency cases were not found (Table 1). 
Table 1 - Distribution of the number of cases and percentage of canine relationship during the deciduous, mixed and permanent dentition

\begin{tabular}{llll}
\hline $\begin{array}{l}\text { Canine } \\
\text { Relationship }\end{array}$ & $\begin{array}{l}\text { Number of cases } \\
\text { Deciduous }\end{array}$ & $\begin{array}{l}\text { Number of cases } \\
\text { Mixed }\end{array}$ & $\begin{array}{l}\text { Number of cases } \\
\text { Permanent }\end{array}$ \\
\hline CL II & $3(3,3 \%)$ & $01(1,1 \%)$ & $13(14,4 \%)$ \\
\hline CL II T & $20(22,2 \%)$ & $17(18,9 \%)$ & $31(34,4 \%)$ \\
\hline CL I & $67(74,5 \%)$ & $72(80 \%)$ & $46(51,2 \%)$ \\
\hline CL III & 0 & 0 & 0 \\
\hline CL III T & 0 & 0 & 0 \\
\hline Total & $90(100 \%)$ & $90(100 \%)$ & $90(100 \%)$ \\
\hline
\end{tabular}

When the canine relationship was analyzed longitudinally, it was possible to observe its development in the mixed and permanent dentition. Figures 1,2 and 3 shows the development of canine relationship during the mixed and permanent dentition, according to its original classification during the deciduous dentition.

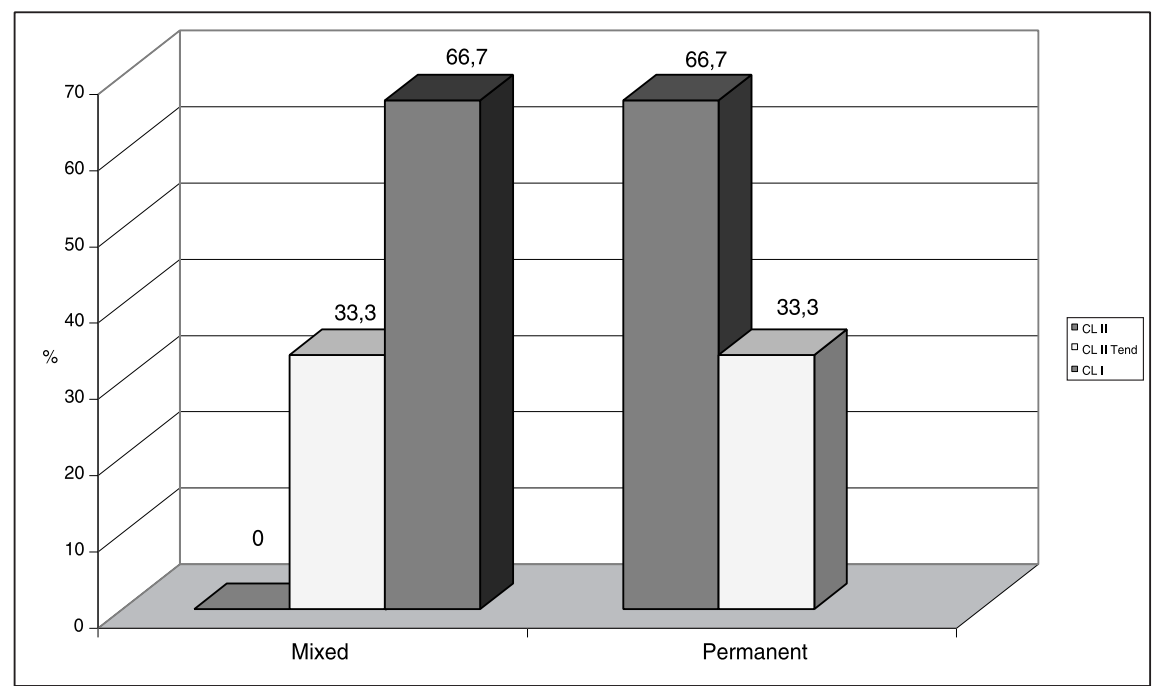

FIGURE 1 - Development of canine relationship in the mixed and permanent dentition (in percentage) in cases diagnosed as Class II canine relationship during the deciduous dentition $(\mathrm{n}=03)$. 


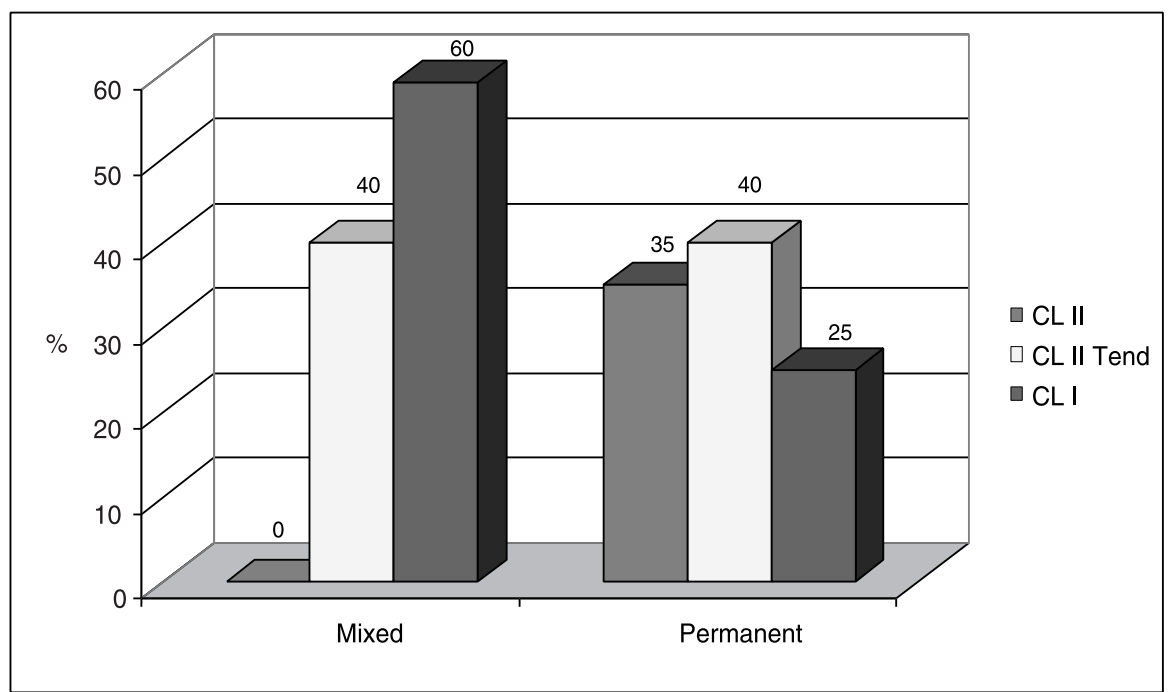

FIGURE 2 - Development of canine relationship in the mixed and permanent dentition (in percentage) in cases diagnosed as Class II tendency canine relationship during the deciduous dentition $(n=20)$.

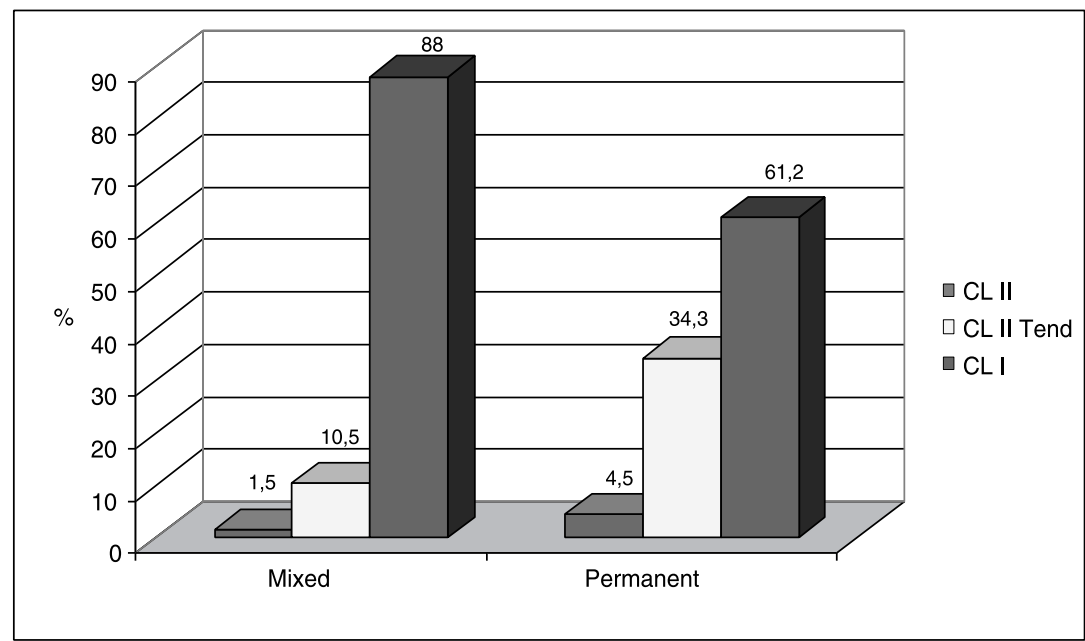

FIGURE 3 - Development of canine relationship in the mixed and permanent dentition (in percentage) in cases diagnosed as Class I canine relationship during the deciduous dentition $(n=67)$.

\section{Discussion}

When considering the alterations present in the canine relatioship, our results revealed that the antero-posterior canine relationship stablished during the deciduous dentition suffered no alterations in $76 \%$ of the total sample. In the sample studied by Foster \& Grundy ${ }^{4}(1986)$ this percentage was of approximately $50 \%$ of the sample composed of 60 patient. However, it is important to point out that when the alteration was present, the great majority of our sample revealed a change in direction to Class II or Class II tendency, in accordance with Foster \& Grundy's results (1986). Our results also indicate that $25 \%$ of the cases diagnosed as Class I during the mixed dentition can suffer an alteration, and the tendency of this alteration was in direction to Class II cases.

In agreement with our results, even the Class I patients should be monitored so much as other patient that present any other malocclusion, because this patient can develop a Class II or Class II tendency during the mixed or permanent dentition, although the majority may suffer no alterations. Some attention should be given during the exfoliation of second primary molars, to avoid an mesial inclination of the first permanent molars. 
For patients that present Class II or even Class II tendency in the deciduous dentition have a more predictable prognostic, according to our results, this patient will also develop to a Class II relationship during the permanent dentition. Treatment planning can begin during the mixed dentition period, simultaneously to the growth and development of patients, in order to avoid the need for extraction of permanent teeth.

Although Class III patients were not found in our sample, it is of general consent among orthodontics and pedodontics that these type of malocclusion can be diagnosed during the deciduous dentition and invariable have no alterations until the permanent dentition is established. These special type of patients may receive an orthodontic treat-

\section{Bibliographic References}

01. ANGLE, E. H. Classification of malocclusion. Dent Cosmos, v.41, n.18, p.248-64, Mar./Apr. 1899.

02. BAUME, L. J. Physiologic tooth migration and its significance for the development of occlusion. I. The biogenesis course of the deciduous dentition. J Dent Res, v.29, n.2, p.123-32, Apr. 1950.

03. BAUME, L. J. Physiologic tooth migration and its significance for the development of occlusion. II. The biogenesis of accesional dentition. J Dent Res, v.29, n.3, p.331-37, June 1950. ment in a vary precocious time (deciduous dentition or early mixed dentition), in order to prevent a surgical intervention in the future.

\section{Conclusions}

a) Class I canine relationship was the most prevalent during the three period studied;

b) Class II tendency cases were the most stable relationship, followed by Class I and Class II cases;

c) The antero-posterior canine relationship stablished during the deciduous dentition suffered no alterations in $76 \%$ of the total sample.

04. FOSTER, T. D.; GRUNDY, M. C. Occlusal changes from primary to permanent dentitions. Br J Orthod, v.13, n.4, p. 187-903, Oct. 1986.

05. MOYERS, R.E., et al. Standards of human occlusal development. The University of Michigan, Ann Arbor, Michigan. Center for Human Growth and Development, 1976. $167 \mathrm{p}$.

06. RIOLO, M.L. et al. An atlas of craniofacial growth. The University of Michigan, Ann Arbor, Michigan. Center for Human Growth and Development, 1974. 114p. 